\title{
Evaluation of a Web-Based Intervention for Multiple Health Behavior Changes in Patients With Coronary Heart Disease in Home-Based Rehabilitation: Pilot Randomized Controlled Trial
}

Yan Ping Duan ${ }^{1}, \mathrm{PhD}$; Wei Liang ${ }^{1}, \mathrm{MEd} ; \mathrm{Lan} \mathrm{Guo}^{2}, \mathrm{PhD}$; Julian Wienert ${ }^{3}, \mathrm{PhD}$; Gang Yan $\mathrm{Si}^{4}, \mathrm{PhD}$; Sonia Lippke ${ }^{3}$, $\mathrm{PhD}$

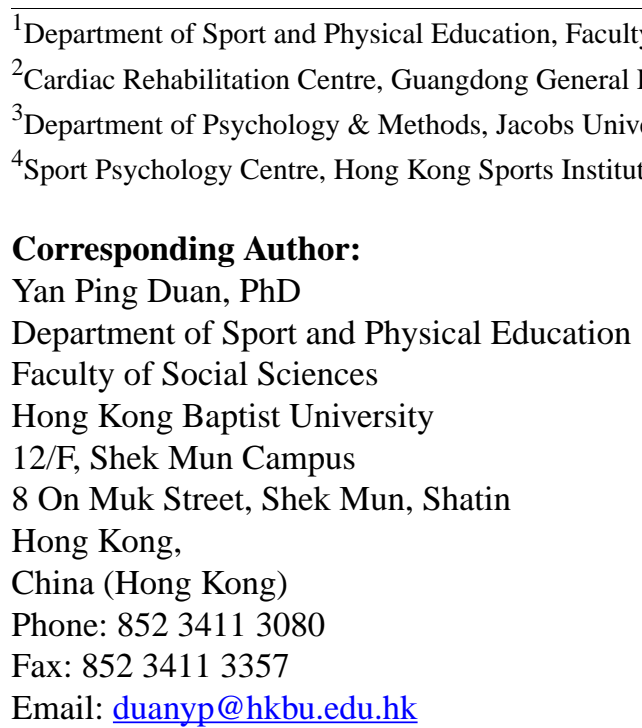

\section{Abstract}

Background: Web-based and theory-based interventions for multiple health behaviors appears to be a promising approach with respect to the adoption and maintenance of a healthy lifestyle in cardiac patients who have been discharged from the hospital. Until now, no randomized controlled trials have tested this assumption among Chinese rehabilitation patients with coronary heart disease using a Web-based intervention.

Objective: The study aim was to evaluate the effect of an 8-week Web-based intervention in terms of physical activity (PA), fruit and vegetable consumption (FVC), lifestyle changes, social-cognitive outcomes, and health outcomes compared with a waiting control group in Chinese cardiac patients. The intervention content was theory-based on the health action process approach. Self-reported data were evaluated, including PA, FVC, healthy lifestyle (the synthesis of PA and FVC), internal resources (combination of intention, self-efficacy, and planning), and an external resource (social support) of PA and FVC behaviors, as well as perceived health outcomes (body mass index, quality of life, and depression).

Methods: In a randomized controlled trial, 136 outpatients with coronary heart disease from the cardiac rehabilitation center of a hospital in China were recruited. After randomization and exclusion of unsuitable participants, 114 patients were assigned to 1 of the 2 groups: (1) the intervention group: first 4 weeks on PA and subsequent 4 weeks on FVC and (2) the waiting control group. A total of 2 Web-based assessments were conducted, including 1 at the beginning of the intervention (T1, $\mathrm{N}=114)$, and 1 at the end of the 8-week intervention (T2, N=83). The enrollment and follow-up took place from December 2015 to May 2016.

Results: The Web-based intervention outperformed the control condition for PA, FVC, internal resources of PA and FVC, and an external resource of FVC, with an eta-squared effect size ranging from 0.06 to 0.43 . Furthermore, the intervention effect was seen in the improvement of quality of life $\left(F_{1,79}=16.36, P<.001, \eta^{2}=.17\right)$. When predicting a healthy lifestyle at follow-up, baseline lifestyle (odds ratio, OR 145.60, 95\% CI 11.24-1886; $P<.001)$ and the intervention (OR 21.32, 95\% CI 2.40-189.20; $P=.006$ ) were found to be significant predictors. Internal resources for FVC mediated the effect of the intervention on the adoption of a healthy lifestyle $\left(R_{\text {adj }}^{2}=.29 ; P=.001\right)$, indicating that if the intervention increased the internal resource of behavior, the adoption of a healthy lifestyle was more likely. 
Conclusions: Patients' psychological resources such as motivation, self-efficacy, planning, and social support as well as lifestyle can be improved by a Web-based intervention that focuses on both PA and FVC. Such an intervention enriches extended rehabilitation approaches for cardiac patients to be active and remain healthy in daily life after hospital discharge.

Trial Registration: ClinicalTrials.gov NCT01909349; https://clinicaltrials.gov/ct2/show/NCT01909349 (Archived by WebCite at http://www.webcitation.org/6pHV1A0G1)

(J Med Internet Res 2018;20(11):e12052) doi: 10.2196/12052

\section{KEYWORDS}

eHealth; physical activity; diet; cardiac rehabilitation; health resources

\section{Introduction}

\section{Background}

Cardiovascular disease (CVD) is the leading cause of death worldwide, with coronary heart disease (CHD) being the major component [1]. In China, CVD was the number one cause of death in 2017, and CHD was the dominant component responsible for $51.6 \%$ of all CVD deaths [2]. Cardiac rehabilitation is widely recognized as an effective intervention to avoid further progression and relapse of CVD [3-5]. CHD patients receive the guidance provided on healthy lifestyle changes regarding physical activity (PA) and a healthy diet during rehabilitation in the hospital $[6,7]$. However, several studies have revealed that it is often difficult for patients to integrate and transfer these recommendations and learning outcomes into their daily life after discharge from the hospital $[8,9]$. Thus, they need internal and external resources, which can be supported by an extended rehabilitation aftercare when they are at home [10].

With the prevalence of internet use, Web-based interventions are widely developed and applied in the field of cardiac rehabilitation [11-13]. The effectiveness of Web-based interventions on PA and fruit and vegetable consumption (FVC) has been proven to facilitate healthy lifestyle changes after discharge among cardiac patients and people with cardiovascular risk profiles in the Western Hemisphere [14-16]. However, in the Eastern Hemisphere, and especially in China, a large body of Web-based rehabilitation interventions only focus on knowledge, education, and learning. Very few integrate individualized and comprehensive interventions that include educational, cognitive, and psychological elements [17,18].

This study applied the Health Action Process Approach (HAPA) [8] as the theoretical backdrop, which suggests that there are 2 distinctive phases during the health behavior change process. The first phase is the motivation phase, which plays an important role before a goal is set. Subsequently, individuals enter the volition phase, which plays an important role in planning and maintaining health behavior changes. This distinction allows interventions to be tailored based on variables that correspond to either the motivation or the volition phase. In particular, motivation must be built up before individuals can actually change unhealthy behaviors (eg, physical inactivity). Therefore, individuals with an unhealthy lifestyle and no intention to change it might benefit most from interventions that will increase risk perception, self-efficacy, and positive outcome expectancies, to support the formation of goal intentions that focus on healthy lifestyle changes [19]. The purpose is to lead toward a specific intention (eg, "I intend to eat five portions of fruit and vegetables today"). Once the intention is formed and the goal is set, individuals enter the volition phase.

In the volition phase, people benefit most from planning interventions, which can help cross the so-called intention behavior gap [14]. In this phase, individuals learn how to make specific plans (eg, when, where, and how to eat fruit and vegetables), determine priorities, and translate their action plans into behavior. Such self-regulatory planning skills are necessary to maintain progress once people initiate a healthy behavior. Positive behavior change will be guided by self-efficacy, as self-efficacy regulates how much effort is invested in goal achievement, and how much persistence is maintained if obstacles and setbacks occur. In addition, promoting behavior-specific social support from people's social context is equally important in preventing relapse [8]. In general, cardiac rehabilitation patients need internal (forming and improving intention, self-efficacy, and planning) and external (forming behavior-specific social support) resources to support them to adopt and maintain a healthy lifestyle after their discharge from the hospital.

Until now, how internal and external resources interplay with lifestyle change in cardiac patients (eg, following recommendations for PA and FVC) has not been fully addressed. Interventions that integrate both internal and external resources may enhance social cognitions, which in turn can lead to the adoption of a healthy lifestyle. Thus, mediation analysis might disclose the underlying mechanisms of such an intervention. All of this has been researched in the Western Hemisphere $[15,20]$ but not in the Eastern Hemisphere, and therefore, the purpose of this study is to fill this gap.

\section{Aim and Hypotheses}

The main research aim of this study was to examine the efficacy of an 8-week Web-based intervention compared with a waiting control group (WCG) to improve PA and FVC in Chinese rehabilitation patients with CHD after hospital discharge. Effects on single health behaviors, healthy lifestyle (the synthesis of PA and FVC), social-cognitive indicators for PA and FVC (internal and external resources), and perceived health outcomes (body mass index [BMI], quality of life, and depression) were tested (see hypotheses 1 to 3 ). The second aim of this study was to examine whether changes in internal resources (combination of intention, self-efficacy, and planning) and an external resource (social support) mediate the effect of the intervention on changes in lifestyle (hypothesis 4). 
The main intervention effects were hypothesized in terms of (1) self-reported increase in PA and FVC behavior (single behavior indicators; hypothesis 1a) and adoption of a healthy lifestyle (hypothesis 1b); (2) more improvements in indicators of internal resources (combination of intention, self-efficacy, and planning) and an indicator of external resources (social support; hypothesis 2); (3) improvement in health outcomes (BMI, quality of life, and depression level; hypothesis 3); and (4) the expectation that those patients who had increased internal resources (combination of intention, self-efficacy, and planning) and an external resource (social support) because of the intervention would be more likely to adopt a healthy lifestyle (mediation effect; hypothesis 4).

\section{Methods}

\section{Study Design, Procedure, and Participants}

This study was a pilot randomized controlled trial involving 1 intervention group (IG) and 1 WCG. There were 2 assessments: a pretest after randomization and before intervention start or the waiting time $(\mathrm{T} 1, \mathrm{n}=114)$ and a posttest at 8 weeks after the pretest $(\mathrm{T} 2, \mathrm{n}=83)$. The WCG was allowed to access the 8 -week Web-based intervention after T2, once the IG had finished the intervention. All patients were informed about the purpose of the study with an informed consent form. The study received ethical approval by the Committee for the Use of Human \& Animal Subjects in Teaching \& Research of Hong Kong Baptist University (FRG1/12-13/064) and was registered with ClinicalTrials.gov (NCT01909349; Multimedia Appendix 1 [12]).

Enrollment and follow-up took place from December 2015 to May 2016. Outpatients with CHD were recruited face-to-face by the physician of the research team, with the assistance of a nurse in the cardiac rehabilitation center of a hospital in south China. The inclusion criteria were as follows: aged between 18 and 75 years, no restriction of physical mobility under the cardiac function at entry, no restriction of other relevant diseases such as diabetes or fruit allergies, sufficient reading and writing skills in Chinese, internet access via a computer at home, and mobile access.

Figure 1 shows the flowchart of patients from enrollment in the study to allocation to the 2 groups (IG and WCG) and posttest after 8 weeks. A total of 136 patients with CHD were recruited. Of these, $16.2 \%(22 / 126)$ were excluded after random allocation due to restrictions in terms of PA or FVC $(n=11)$, no internet access via a computer at home $(n=4)$, or because they declined to participate $(n=7)$. Subsequently, $83.8 \%$ (114/136) eligible patients fulfilled the online registration and provided personal information within 1 week during the period of hospital rehabilitation. In total, 60 patients $(52.6 \%)$ in the IG and 54 patients $(47.4 \%)$ in the WCG were included. During the last week before they were discharged from the hospital, patients in both groups were invited to complete the first online questionnaire (pretest; T1). Patients in the IG were encouraged to access a Web-based health program via their home computer once a week during the following 8 weeks, whereas patients in the WCG did not receive any treatment. Upon completion of the 8-week intervention, patients in both groups were invited to fill in the second online questionnaire (posttest; T2). The final longitudinal sample consisted of $83(72.8 \%)$ patients, including $44(53 \%)$ in the IG, and $39(47 \%)$ in the WCG (Figure $1)$.

All website links for the questionnaire surveys at T1 and T2 as well as for the weekly intervention program were delivered via email. To boost the engagement of patients, short message service (SMS) text messages were sent as reminders. Furthermore, the nurse contacted participants via phone calls once per week before each intervention session and at the 2 measurement points to remind the patients. Moreover, patients were offered a 60 renminbi (RMB; US \$9) telephone recharge card as an incentive in exchange for their participation in the study and completion of the 2 data collection waves.

\section{Intervention}

The 8-week Web-based intervention started with PA in the first 4 weeks, followed by the FVC in the later 4 weeks. This sequential design falls into the previous study results, suggesting PA might act as gateway behavior [21,22], and PA modules are the most favored modules in tailored electronic health (eHealth) lifestyle promotion [23].

The intervention content was designed based on the HAPA theory. Accordingly, social-cognitive variables of PA and FVC were targeted in the intervention (Multimedia Appendix 2). In particular, the targeted variables were as follows: week 1 and week 5-risk perception, outcome expectancies, and goal setting; week 2 and week 6 - development of action plans; week 3 and week 7-revision and adjustment of previous action plans and development of coping plans; and week 4 and week 8 -revision and adjustment of previous coping plans and development of behavior-specific social support. Self-efficacy was a fixed intervention variable that was included from week 1 to week 8. Multimedia Appendix 2 indicates intervention variables and content for each week.

In addition, selected behavior change techniques were addressed in the intervention to facilitate the implementation and maintenance of behavior [24]. For example, 2 types of feedback were provided: patients received individualized feedback on their self-reported behavior performance 4 weeks ago, 3 weeks ago, 2 weeks ago, and 1 week ago. Criterion-based feedback was also presented (eg, accumulated at least $150 \mathrm{~min}$ with moderate intensity of PA per week and 5 portions of FVC per day). The examples of the feedback can be found in a separate publication [25]. Moreover, examples of role models were provided throughout the intervention to support patients to set goals, develop plans, and increase their self-efficacy.

\section{Measures}

All variables were self-reported online at pretest (T1) and posttest after the 8-week intervention period (T2).

\section{Demographic Information}

Sociodemographic information such as gender, age, level of education (low-level: primary school; high-level: high school, and university or college), and relationship status (single or in a relationship) was assessed. In addition, self-reported body height $(\mathrm{cm})$ and weight $(\mathrm{kg})$ were collected at T1 and T2. 
Figure 1. Flowchart of participant progress throughout the study phases. FVC: fruit and vegetable consumption; PA: physical activity.

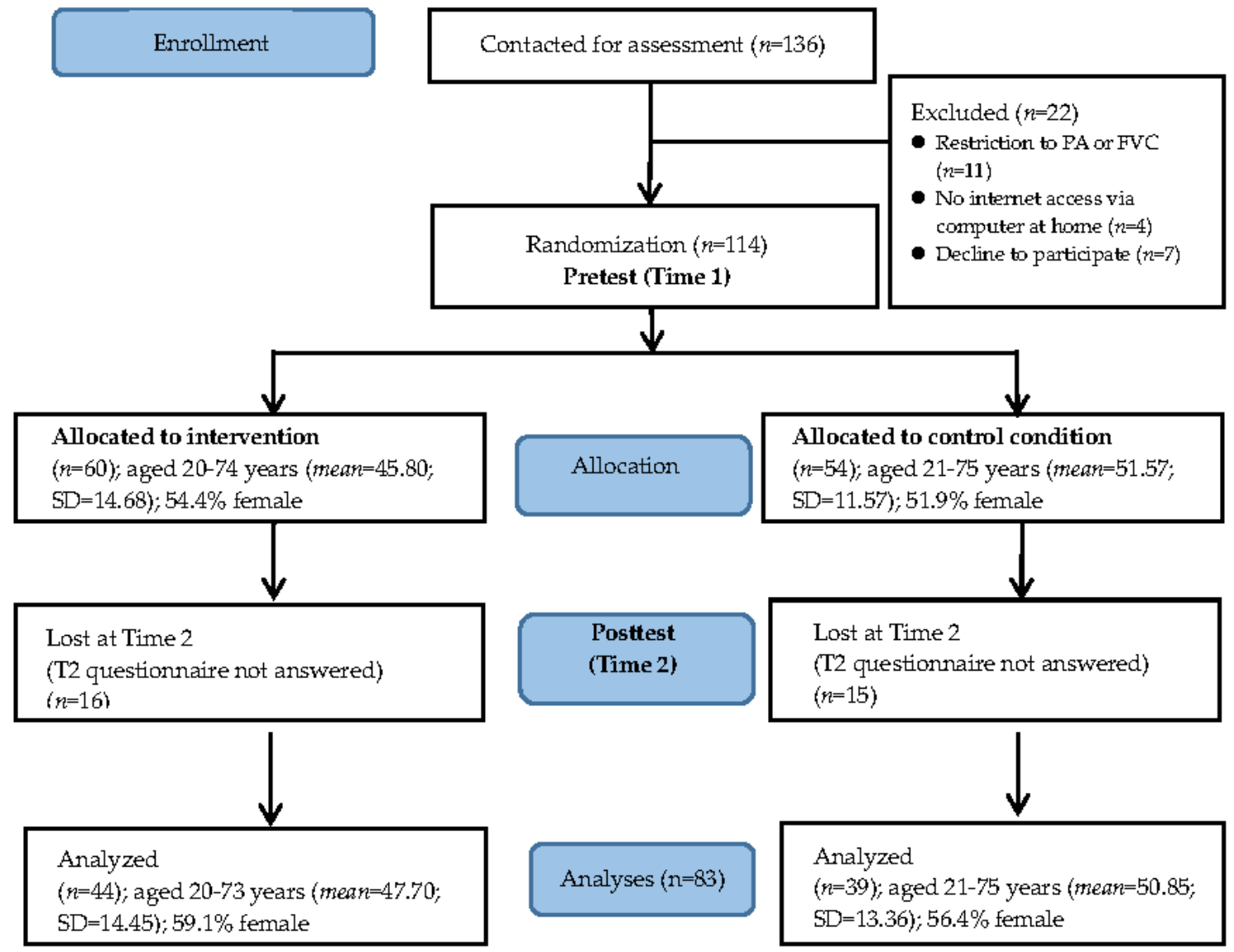

\section{Health Behavior (Single Behavior Indicators)}

The level of PA was assessed using an adaption of the Chinese short version of the International Physical Activity Questionnaire [26]. Patients indicated how often per week and how long each time they performed vigorous PAs (eg, fast bicycling and intensive swimming) and moderate physical activities (eg, carrying light loads and bicycling at a regular pace) during the last week. The total PA score (in min/week) for each patient was obtained by summing up all questions.

FVC during the past 7 days was assessed with 4 items, including raw vegetables, fruits, fruit or vegetable juice, and cooked or steamed vegetables [27]. For each item, patients were asked to count the number of portions or glasses of liquid, fruit, and vegetables they consumed on average per day (11 options such as $0,0.5,1,1.5,2,2.5 \ldots, 5$, or above). The total consumed portion was the sum of each item.

\section{Combined Healthy Lifestyle Indicator}

To combine the 2 behaviors, PA and FVC behaviors were categorized according to whether or not the patients met the health recommendations [20]. After exploring the usefulness of different criteria, the thresholds of $150 \mathrm{~min}$ of PA with moderate intensity per week and 5 portions of fruit and vegetables were chosen. Both criteria were validated and have been shown to be effective in improving health [28,29]. At T1, $60 \%$ of patients (50/83 eligible patients participating in $\mathrm{T} 1$ and T2) did not perform 150 or more min of PA with moderate intensity per week. Moreover, 71\% (59/83) of patients did not eat 5 or more portions of fruit and vegetables per day. When both behaviors were combined, $84 \%$ (70/83) participants met only 1 or none of these 2 behavioral criteria and were categorized as having an unhealthy lifestyle at T1. Overall, 15\% $(13 / 83)$ of the patients met both behavior recommendations and were categorized as having a healthy lifestyle.

At T2, 50\% of patients (42/83 eligible patients participating in $\mathrm{T} 1$ and T2) did not perform 150 or more min of PA with moderate intensity per week. In addition, $60 \%$ (50/83) of patients did not eat 5 or more portions of fruit and vegetables per day. When both behaviors were combined, $73 \%$ (61/83) of participants met only 1 or none of these 2 behavioral criteria and were categorized as having an unhealthy lifestyle at T1. In total, $26 \%(22 / 83)$ of patients met both behavior recommendations and were categorized as having a healthy lifestyle. 


\section{Social-Cognitive Indicators as Internal Resources of Behavior Change}

\section{Intention}

Intention concerning PA was measured with the stem "On 5 days a week for $30 \mathrm{~min}$, I have the intention to perform..." followed by 3 items such as "...strenuous sports activities," "...moderate PA," and "...mild PA, like walking" (Cronbach alpha=.40) [30]. Intention concerning FVC was assessed by the stem "I intend to..." followed by 3 items such as "...eat at least 5 servings of fruits and vegetables each day," "...eat fruit and vegetables at every meal," and "drink at least one fruit or vegetable juice every day" (Cronbach alpha=.51) [30]. The answers were indicated on a 4-point scale ranging from 1 "not true" to 4 "exactly true."

\section{Self-Efficacy}

Self-efficacy for PA was assessed with 5 items such as "I am certain that I can permanently be physically active for at least 5 days a week for 30 minutes each day" (Cronbach alpha=.89) [31]. Self-efficacy for FVC was assessed by 5 items such as "I am certain that I can eat 5 portions of fruits and vegetables a day, even if it is sometimes difficult" (Cronbach alpha=.95) [32]. The answers were given on a 5-point scale ranging from 1 "don't agree at all" to 5 "totally agree."

\section{Planning}

The planning indicator was categorized into action planning and coping planning. Action planning was assessed by the stem "For the next month I have carefully planned..." followed by 3 items for PA such as "...which PA I will pursue" (Cronbach alpha=.94) or followed by 3 items for FVC such as "....what I will eat" (Cronbach alpha=.91) [32,33]. Coping plans were measured by the stem "For the next month I have carefully planned..." followed by 3 items for PA such as "...What I can do in difficult situations to stick to my intentions" (Cronbach alpha=.90) or followed by 3 items for FVC such as "...How I can eat healthy, even if something happened" (Cronbach alpha=.92) $[32,33]$. The answers were given on a 5-point scale ranging from 1 "strongly disagree" to 5 "strongly agree."

\section{Social-Cognitive Indicator as External Resources of Behavior Change}

\section{Social Support}

This indicator was measured with 3 items for PA (Cronbach alpha=.72) and with 3 items for FVC (Cronbach alpha=.87) such as "My partner helps me/my family helps me/my friends and acquaintances help me to stay physically active" or "My partner helps me/my family helps me/my friends and acquaintance help me to eat healthy." Answers were given on a 4-point scale ranging from 1 "totally disagree" to 4 "totally agree" [34].

\section{Health Outcomes}

\section{Body Mass Index}

BMI was calculated using the formula "BMI=weight $(\mathrm{kg}) / \mathrm{height}$ $\left(\mathrm{m}^{2}\right)$." Body weight and body height were reported by the study participants.

\section{Quality of Life}

This indicator was measured using the Hong Kong version of the World Health Organization's Quality of Life questionnaire (Brief version) [35]. Respondents were first asked about their general quality of life by the item "How would you rate your quality of life?" Study participants were assessed with a 5-point scale ranging from 1 "very poor" to 5 "very good" and by 7 items on physical health subdomains. Such subdomains were "How satisfied are you with your ability to perform your daily living activities?" Response categories used a 5-point scale ranging from 1 "very dissatisfied" to 7 "very satisfied" (Cronbach alpha=.87).

\section{Depression}

Level of depression was measured using the Chinese translated Center for Epidemiological Studies-Depression (CES-D) scale. Respondents were asked with the stem "In the past week how often I feel..." followed by 20 items such as "...I was bothered by things that usually don't bother me." Respondents were asked to indicate the frequency of symptoms on a 4 -point scale $(0=$ less than a day, $1=1$ to 2 days, $2=3$ to 4 days, $3=5$ to 7 days). Positively formulated items were reversed. The total score consisted of the sum of all 20 items and ranged from 0 to 60 (Cronbach alpha=.88). A CES-D score $\geq 16$ indicated the likelihood of a clinically significant depression [36].

All questionnaires above stem from validated and well-tested measurement tools in the Chinese version used in previous studies $[25,26,35,36]$. In addition, pretests were conducted to ensure the usability and technical functionality of the electronic versions of the questionnaires before the main study.

\section{Data Analysis}

All data analyses were performed using IBM SPSS 24.0. The analyses of dropout and comparison of participant characteristics at $\mathrm{T} 1$ were conducted with independent sample $t$ tests and chi-square tests. The 5\% level (2-tailed) was used as the statistical significance cutoff point.

Intervention effects on PA and FVC behaviors (hypothesis 1a) were tested with repeated-measures analysis of variance (ANOVA). Hypothesis $1 \mathrm{~b}$ on the combined healthy lifestyle indicator was tested using chi-square and logistic regression analysis (determining odds ratio, OR). In addition, intervention effects on social-cognitive variables (indicators of internal resources and external resources; hypothesis 2) and health outcomes (BMI, quality of life, and depression level; hypothesis 3) were evaluated by conducting a series of repeated-measures analyses of covariance (ANCOVA) with baseline behavior as the covariate. The 2 factors for both ANOVAs and ANCOVAs were time (T1 and $\mathrm{T} 2$ ) as the within-participants factor and treatment (IG vs WCG) as the between-participants factor. Hypothesis 4 on the multiple mediation models was performed using an SPSS macro [37]. Before the mediation analysis, the diagnostics of multicollinearity were performed. The criteria of serious multicollinearity problem include high correlation $(r>.85)$, low tolerance $(\leq 0.01)$, high variance inflation factor (VIF $>10)$, low eigenvalue (approach zero), and large condition index (>30) among mediators [38]. Residualized change scores were used, and $95 \%$ CIs of the standardized effects of the 
intervention were estimated by applying the bootstrap approach (5000 bootstrap samples).

Results were reported based on those cardiac patients who participated in both measurement points. As less than 5\% of items were missing and belonged to a randomized distribution, the expectation-maximization method was adopted to impute the missing data within each measurement point in time [39].

\section{Results}

\section{Sample Characteristics and Randomization Check}

There were 114 cardiac patients who participated in data collection at $\mathrm{T} 1(\mathrm{IG}=60, \mathrm{WCG}=54)$, and 83 of them completed data collection at $\mathrm{T} 2(\mathrm{IG}=44, \mathrm{WCG}=39)$. The dropout rate of participants was $27.2 \%$ (31/114) from T1 to T2. For participants in the IG, 44 (T2) out of 60 (T1) patients (73\%) adhered to the whole 8 -week intervention program. The 83 final patient sample included more females $(57 \%, 48 / 83)$ than males, aged from 20 to 75 years (mean=49.18 years, $\mathrm{SD}=13.96)$. The majority of patients were in a relationship $(94 \%, 78 / 83)$. Most patients had a high education level $(89 \%, 74 / 83)$. The average BMI of patients was 23.65 (SD 2.89, range 16.71-31.25).

Participants at $\mathrm{T} 1$ and $\mathrm{T} 2$ did not significantly differ from dropouts at $\mathrm{T} 2$ regarding the gender $\left(\chi_{1}^{2}=2.3, P=.13\right)$, education level $\left(\chi_{1}^{2}=1.6, P=.20\right)$, relationship status $\left(\chi_{1}^{2}=0.3, P=.56\right)$, age $\left(t_{112}=-0.77, P=.44\right)$, amount of PA at T1 $\left(t_{109}=-1.78, P=.08\right)$, and $\mathrm{FVC}$ at $\mathrm{T} 1\left(t_{108}=-0.88, P=.38\right)$.

Results also indicated that there were no significant differences across the 2 groups at $\mathrm{T} 1$ with respect to single behaviors of $\mathrm{PA}$ and FVC, internal resources for PA and FVC (combination of intention, self-efficacy, and planning), an external resource for PA and FVC (social support), age, or health outcomes (BMI, quality of life, and depression; all $P=.11$ to .86). In addition, there were no significant differences between the 2 groups on gender $\left(\chi_{1}^{2}=0.4, P=.54\right)$, education level $\left(\chi_{1}^{2}=0.8, P=.49\right)$, relationship status $\left(\chi_{1}^{2}=0.02, P=.90\right)$, and combined health lifestyle indicator (combination of both behaviors; $\chi_{1}^{2}=0.5$, $P=.50)$.

\section{Evaluation of Time and Treatment on Single-Behavior Indicators as well as Social-Cognitive Indicators of Behavior Change}

Table 1 presents the evaluation result of the time, treatment, and time $\mathrm{x}$ treatment effect. Out of 6 interaction effects, 5 were statistically significant, with an effect size of $\eta^{2}$ ranging from 0.06 to 0.43 . The mean values of PA, FVC, internal resources of PA, internal resources of FVC, and social support of FVC between 2 groups over time are presented in Figure 2.

Although there was no significant interaction effect on social support for PA $(P=.08)$, the mean value of social support for PA (see Figure 2, panel C) indicated that there was a descriptive difference between the 2 groups, which was clearly in favor of the IG.

\section{Evaluation of Time and Electronic Health Treatment on Combined Healthy Lifestyle Indicators}

As the purpose of the intervention was not only to change single behaviors but also to improve patients' lifestyle including both PA and FVC behaviors, change in the combined health indicator was evaluated. According to their PA and FVC behaviors, patients were categorized into groups based on whether or not they met the recommended criteria. The frequencies and percentage of a healthy and an unhealthy lifestyle at T2 depending on $\mathrm{T} 1$ lifestyle and treatment are presented in Table 2 .

Table 1. Intervention efficacy evaluated in terms of changes over time assessed in a 2-factorial repeated measures analysis of variance.

\begin{tabular}{|c|c|c|c|c|c|c|c|c|c|c|c|c|}
\hline \multirow[t]{2}{*}{ Variables } & \multicolumn{3}{|l|}{ Time } & \multicolumn{3}{|l|}{ Treatment } & \multicolumn{3}{|c|}{ Baseline behavior } & \multicolumn{3}{|c|}{ Interaction time $\mathrm{x}$ treatment } \\
\hline & $F$ test $(d f)$ & $\eta^{2}$ & $P$ value & $F$ test $(d f)$ & $\eta^{2}$ & $P$ value & $F$ test $(d f)$ & $\eta^{2}$ & $P$ value & $F$ test $(d f)$ & $\eta^{2}$ & $P$ value \\
\hline \multicolumn{13}{|c|}{ Physical activity (minutes/week) } \\
\hline Behavior $^{\mathrm{a}}$ & $2.88(1,81)$ & .03 & .09 & $1.33(1,81)$ & .02 & .25 & $\mathrm{~N} / \mathrm{A}^{\mathrm{b}}$ & N/A & N/A & $9.25(1,81)$ & .10 & .003 \\
\hline Internal resources ${ }^{\mathrm{c}}$ & $14.13(1,80)$ & .15 & $<.001$ & $\begin{array}{l}11.17 \\
(1,80)\end{array}$ & .12 & .001 & $\begin{array}{l}13.66 \\
(1,80)\end{array}$ & .15 & $<.001$ & $13.0(1,80)$ & .14 & .001 \\
\hline $\begin{array}{l}\text { External resource } \\
\text { (social support) }\end{array}$ & $3.26(1,80)$ & .04 & .08 & $2.51(1,80)$ & .03 & .12 & $0.19(1,80)$ & $<.01$ & .66 & $3.08(1,80)$ & .04 & .08 \\
\hline \multicolumn{13}{|c|}{ Fruit and vegetable consumption (portions/day) } \\
\hline Behavior & $\begin{array}{l}23.69 \\
(1,80)\end{array}$ & .23 & $<.001$ & 7.27 & .08 & .009 & N/A & N/A & N/A & $\begin{array}{l}59.01 \\
(1,80)\end{array}$ & .43 & $<.001$ \\
\hline Internal resources & $\begin{array}{l}11.06 \\
(1,79)\end{array}$ & .12 & .001 & $9.21(1,79)$ & .10 & .003 & $\begin{array}{l}10.21 \\
(1,79)\end{array}$ & .11 & .002 & $\begin{array}{l}24.96 \\
(1,79)\end{array}$ & .24 & $<.001$ \\
\hline $\begin{array}{l}\text { External resource } \\
\text { (social support) }\end{array}$ & $1.59(1,79)$ & .02 & .21 & $1.05(1,79)$ & .01 & .30 & $0.46(1,79)$ & $<.01$ & .31 & $4.61(1,79)$ & .06 & .04 \\
\hline
\end{tabular}

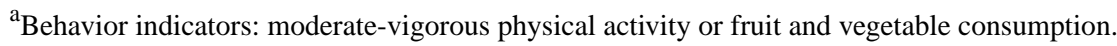

${ }^{\mathrm{b}} \mathrm{N} / \mathrm{A}$ : not applicable.

${ }^{\mathrm{c}}$ Internal resources: intention, self-efficacy, and planning.
} 
Figure 2. Mean values for intervention group (solid line) and waiting control group (dotted line) at T1 and T2. (A) Performed physical activity (PA) (minutes/week). (B) Internal resources for PA (combination of intention, self-efficacy, and planning). (C) External resources for PA (social-support). (D) Fruit and vegetable consumption (FVC) behaviour (portions/day). (E) Internal resources for FVC (combination of intention, self-efficacy, and planning). (F) External resources for FVC (social-support).

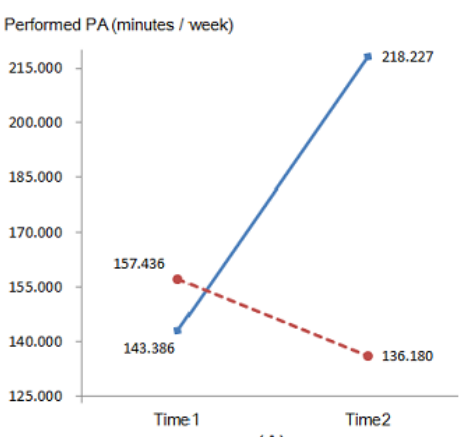

(A)

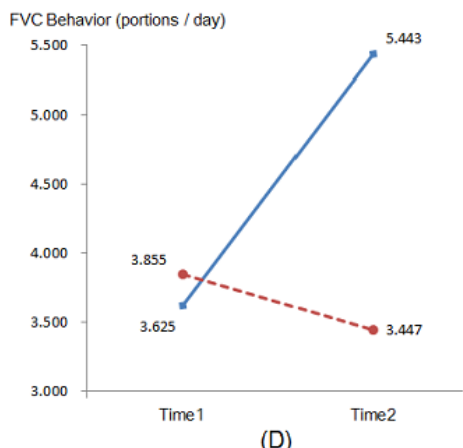

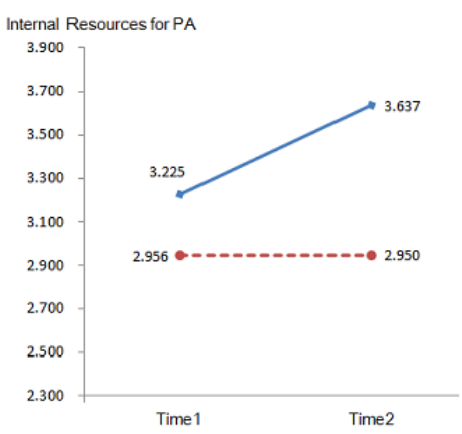

(B)

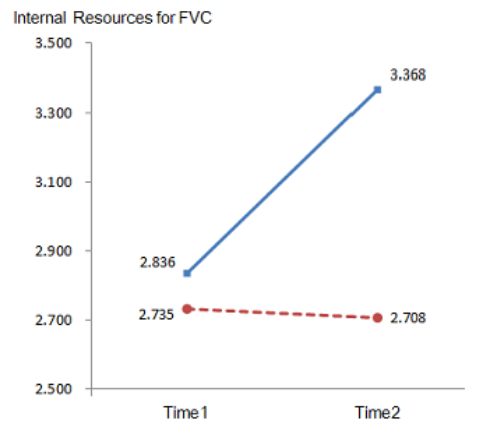

(E)

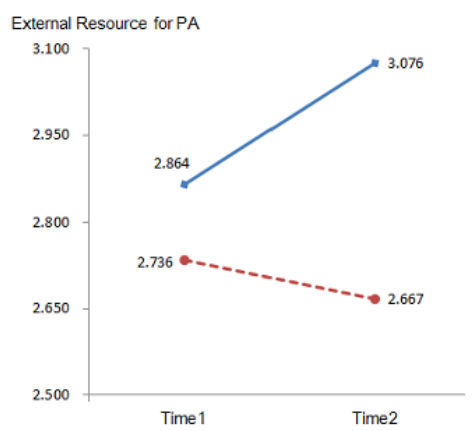

(C)

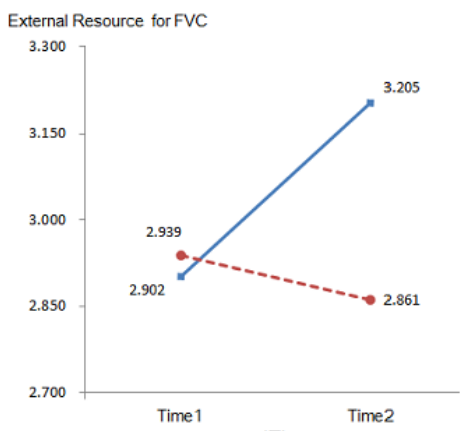

(F)

Table 2. Performance of a healthy and an unhealthy lifestyle at T2 based on lifestyle and treatment at T1.

\begin{tabular}{|c|c|c|c|}
\hline \multirow[t]{2}{*}{ Lifestyle at $\mathrm{T} 1$ and treatment } & \multicolumn{2}{|c|}{ Lifestyle $\mathrm{T}^{\mathrm{a}}{ }^{\mathrm{a}}, \mathrm{n}(\%)$} & \multirow[t]{2}{*}{ Total, $\mathrm{N}$} \\
\hline & Unhealthy T2 & Healthy T2 & \\
\hline \multicolumn{4}{|l|}{ Unhealthy T1 } \\
\hline Intervention group & $26(72)$ & $10(28)$ & 36 \\
\hline Control group & $33(97)$ & $1(3)$ & 34 \\
\hline \multicolumn{4}{|l|}{ Healthy T1 } \\
\hline Intervention group & $0(0)$ & $8(100)$ & 8 \\
\hline Control group & $2(40)$ & $3(60)$ & 5 \\
\hline \multicolumn{4}{|l|}{ Unhealthy and Healthy T1 } \\
\hline Intervention group & $26(59)$ & $18(41)$ & 44 \\
\hline Control group & $35(90)$ & $4(10)$ & 39 \\
\hline Total & $61(74)$ & $22(27)$ & 83 \\
\hline
\end{tabular}

${ }^{\mathrm{a}}$ Lifestyle $\mathrm{T} 1$ or $\mathrm{T} 2=1$ indicates meeting both behavior recommendations (conducting $\geq 150$ min of moderate-vigorous physical activity per week and adopting $\geq 5$ portions of fruit and vegetables per day); lifestyle $\mathrm{T} 1$ or $\mathrm{T} 2=0$ indicates not meeting both behavior recommendations (conducting $\geq 150$ min of physical activity per week and adopting $\geq 5$ portions of fruit and vegetables per day).

Descriptively, among those with an unhealthy lifestyle at T1, lifestyle through treatment compared with only 10\% of (4/39) the IG outperformed the WCG in performing healthy lifestyle patients in the WCG. However, due to the small sample size, behavior (ie, $24.9 \%$ more). For those with a healthy lifestyle at the differences could not be statistically tested.

$\mathrm{T} 1,100 \%(8 / 8)$ of patients in the IG still maintained their healthy lifestyle throughout treatment, compared with only $60 \%$ of patients in WCG. If all patients were considered together, it was found that $40 \%(18 / 44)$ of patients in the IG adopted a healthy

To further explore which variables predict healthy lifestyle behavior at $\mathrm{T} 2$, logistic regression analyses were employed with 3 models (Table 3). First, gender and age (all at T1) were used 
as predictors for the adoption of a healthy lifestyle at T2. Neither of these 2 variables, however, was a significant predictor $(P=.30$ to .47$)$. Lifestyle at $\mathrm{T} 1$ was then added as a predictor in model 2 , which exhibited a significant correlation to a healthy lifestyle at T2: patients who had a healthy lifestyle at T1 were about 47.51 times more likely to also adopt or maintain a healthy lifestyle at T2 (Table 3). Furthermore, the treatment was included as a predictor in model 3 , which was also a significant predictor for a healthy lifestyle at T2 $(P \leq .006$; Table 3$)$. In other words, those patients receiving the intervention were about 21.32 times more likely to practice or maintain a healthy lifestyle in comparison with patients in the control group. With model 3 , lifestyle at $\mathrm{T} 1$ and treatment could attribute to $37 \%$ of the variance of a healthy lifestyle at $\mathrm{T} 2$.

\section{Evaluation of Time and Electronic Health Treatment on Health Outcomes}

Analyses of the time and treatment effect on health outcomes in terms of BMI, quality of life, and depression level were performed. A significant difference was yielded for the interaction factor (time $\mathrm{x}$ treatment) on quality of life $\left(F_{1,79}=16.36, \quad P<.001, \eta^{2}=.17\right)$. Regarding the BMI and depression level, however, the interaction of time and treatment were not significant, respectively $\left(\mathrm{F}_{1,78}=3.35, P=.07, \eta^{2}=.04\right.$; $\left.F_{1,80}=0.001, P=.98, \eta^{2}<.001\right)$. The mean values for BMI, quality of life, and depression at T1 and T2 are displayed in Figure 3.

\section{Testing Mechanism of How the Electronic Health Treatment Facilitated a Healthy Lifestyle}

Finally, a multiple mediator analysis tested whether the effects of the intervention on lifestyle change could be explained by changes in internal and external resources (Figure 4). The multicollinearity diagnostics indicated that there was no serious multicollinearity problem among mediators $(r=0.26-0.55$, tolerance $=0.48-0.60, \mathrm{VIF}=1.66-2.07$, eigenvalue $=0.25-2.43$, and condition index $=1.00-3.11$ ). Residualized change scores obtained by regression $\mathrm{T} 2$ scores on $\mathrm{T} 1$ scores were chosen for the proposed mediators (Figure 4). Group assignment predicted changes in all social-cognitive variables, in particular, in internal resources for PA (beta=.44, SE .81; $P<.001$ ), external resource for PA (beta=.25, SE .94; $P=.02$ ), internal resources for FVC (beta=.57, SE .68; $P<.001$, shown in bold in Figure 4), and external resource for FVC (beta=.28, SE .92; $P=.009$ ). Lifestyle change, as operationalized by meeting the recommendation toward PA and FVC, was predicted by changes in internal resources for FVC (beta=.54, SE .13; $P<.001$, shown in bold in Figure 4) and by no other variables. After controlling for changes in these predictor variables, the relation between group assignment and behavior change was no longer significant (beta=.26, SE .23; $P=.27$; without controlling: beta=.74, SE .21; $P<.001$ ), which indicates that internal resources for FVC was a full mediator of the intervention effectiveness. The multiple mediator model accounted for $33 \%$ of the variance $\left(\mathrm{R}^{2}{ }_{\text {adj }}=.29\right.$; $P=.001)$ in lifestyle.

Table 3. Predicting lifestyle at $\mathrm{T} 2$.

\begin{tabular}{|c|c|c|c|c|c|c|}
\hline \multirow[t]{2}{*}{ Variable } & \multicolumn{2}{|l|}{ Model 1} & \multicolumn{2}{|l|}{ Model 2} & \multicolumn{2}{|l|}{ Model 3} \\
\hline & OR $(95 \% \mathrm{CI})$ & $P$ value & OR $(95 \% \mathrm{CI})$ & $P$ value & OR $(95 \% \mathrm{CI})$ & $P$ value \\
\hline Constant & 0.71 & $\mathrm{~N} / \mathrm{A}^{\mathrm{a}}$ & 0.05 & N/A & 0.002 & N/A \\
\hline Gender & $1.46(0.53-4.04)$ & .47 & $2.60(0.65-10.29)$ & .18 & $2.89(0.65-12.79)$ & .16 \\
\hline Age & $0.98(0.95-1.02)$ & .30 & $1.01(0.97-1.06)$ & .56 & $1.03(0.98-1.08)$ & .30 \\
\hline Lifestyle in $\mathrm{T} 1^{\mathrm{b}}$ & N/A & & $47.51(6.97-324.02)$ & $<.001$ & $145.60(11.24-1886)$ & $<.001$ \\
\hline Treatment $^{\mathrm{c}}$ & N/A & & N/A & & $21.32(2.40-189.20)$ & .006 \\
\hline $\mathrm{R}^{2}$ & .02 & $<.05$ & .27 & $<.001$ & .39 & $<.001$ \\
\hline$\triangle \mathrm{R}^{2}$ & N/A & N/A & .25 & $<.001$ & .12 & $<.001$ \\
\hline
\end{tabular}

${ }^{\mathrm{a}} \mathrm{N} / \mathrm{A}$ : not applicable.

${ }^{\mathrm{b}}$ Lifestyle $\mathrm{T} 1$ or $\mathrm{T} 2=1$ indicates meeting both behavior recommendations (conducting $\geq 150$ min of physical activity/week and adopting $\geq 5$ portions of fruit and vegetables/day); lifestyle $\mathrm{T} 1$ or $\mathrm{T} 2=0$ indicates not meeting both behavior recommendations (conducting $\geq 150$ min of moderate-vigorous physical activity/week and adopting $\geq 5$ portions of fruit and vegetables/day).

${ }^{\mathrm{c}}$ Treatment: 0 indicates waiting control condition; 1 indicates intervention condition. 
Figure 3. Mean values of health outcomes (Body mass index, quality of life, and depression) for intervention group (solid line) and waiting control group (dotted line) at T1 and T2. (A) Body mass index. (B) Quality of life. (C) Depression.
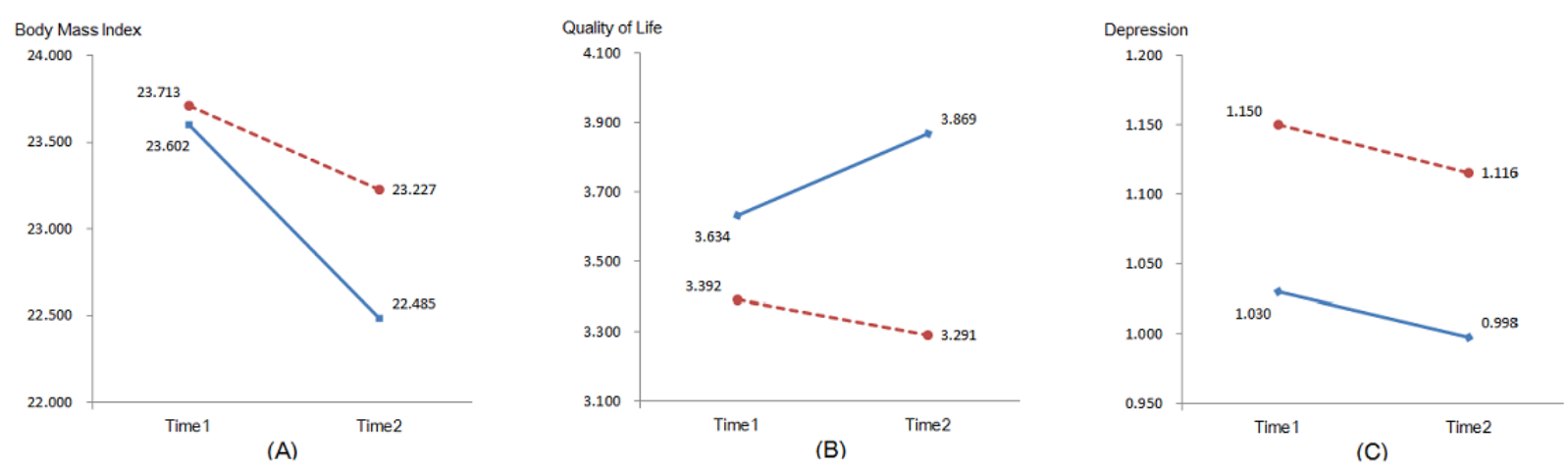

Figure 4. Mediation of the effect of the intervention on lifestyle changes by internal and external resources. Significant changes are indicted by an asterisk.

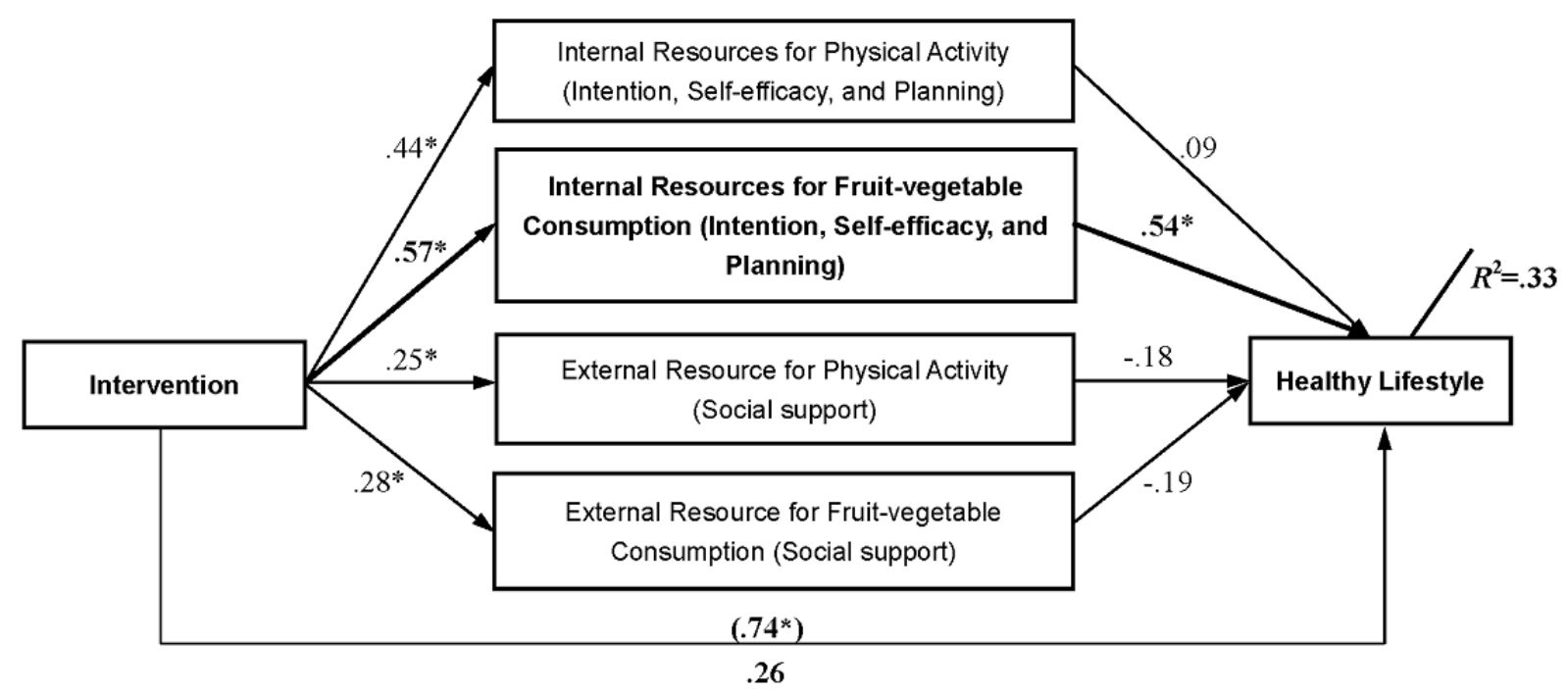

\section{Discussion}

\section{Principal Findings}

The aim of this study was to gain insights into an 8-week Web-based health promotion intervention for Chinese cardiac rehabilitation patients after discharge from hospital. The majority of the research hypotheses were supported.

The main expected intervention effects on single behavior and combined lifestyle were identified. Compared with patients in the control group, patients in the IG reported significantly less decrease of PA and FVC over time (hypothesis 1a). The findings on multiple behavior change are in line with previous studies, which showed effects on both behaviors for patients with metabolic syndrome [40,41].
Furthermore, testing the effect of the intervention on lifestyle indicated that more patients in the IG than in the control group improved their lifestyle by meeting the recommendations for PA and FVC, with a 21 times higher likelihood to practice or maintain a healthy lifestyle in comparison with patients in the control group, after controlling for baseline behavior (hypothesis 1b). In addition, patients who already had a healthy lifestyle at baseline were 47 times more likely to engage in a healthy lifestyle than patients in the control group, after controlling for gender and age, which were both insignificant. The effect of baseline behavior matches previous findings. For instance, this was found in another study targeting employees at the workplace [20] and in rehabilitation settings in North America and Europe $[15,33,42]$. The findings of this study performed in China support the merits of a Web-based extended program for cardiac rehabilitation patients to improve their lifestyle and thus comparably improve their health, for the Western and the 
Eastern Hemisphere. Taking the different findings together, hypothesis $1 \mathrm{a}$ and hypothesis $1 \mathrm{~b}$ were confirmed.

The hypothesized intervention effects on internal (combination of intention, self-efficacy, and planning) and external (social support) resources of behaviors were also identified -3 out of 4 social-cognitive test variables were found to be significant. The Web-based intervention increased the internal resources in the PA domain; it was even able to improve nutrition-related internal and external resources compared with the control group. The majority of hypothesis 2 was confirmed.

When testing the hypothesis on the intervention effects on health outcome, we found patients in the IG were more successful in improving their quality of life, which is coherent with the latest literature using a similar intervention program among university students [25]. However, the significant time $\mathrm{x}$ treatment interaction was not detected for BMI, although differential intervention effects surfaced on a descriptive level. In a systematic review on interactive computer-based interventions for weight loss or weight maintenance in overweight or obese people, it was indicated that treatment duration of such interventions significantly leading to weight loss is 6 months [42]. Likewise, the reduction of BMI through Web-based interventions in cardiac patients also needs long-term treatment duration in the future. In addition, we did not find the expected intervention effect on depression. The possible cause might be that the high percentage of cardiac rehabilitation patients $(68 \%$, $56 / 82$ ) who reported their depression score at the start of the study was equal or higher than 16 , which reflects the critical mental status of many patients. To reduce depression levels in cardiac patients, long-term and combined provision of guidance, information, stress management, and relaxation skills incorporated into the intervention would need to be developed in the future. This suggestion is also supported by another intervention study in rehabilitation patients with myocardial infarction [43]. Overall, hypothesis 3 was confirmed with one-third of the tested variables.

The hypothesized changes in internal and external resources of behavior change (combination of intention, self-efficacy, and planning; social support) were found in the majority of the tested variables in the mediation analysis. In addition, based on the sequential intervention mode in this study (first 4 weeks for PA, followed by latter 4 weeks for FVC), the gateway effect of the PA mechanism on nutrition was confirmed with the increasing close relationship from PA to nutrition on internal $\left(R^{2}\right.$ from .44 to .57$)$ and external $\left(R^{2}\right.$ from .25 to .28$)$ resources, which was also found before $[23,44]$. However, internal resource for FVC was the only facilitator of the intervention effectiveness. In particular, in the mediation model, it was found that patients in the IG who gained more internal resources on nutrition (eg, increased intention, higher self-efficacy, and more specific planning; Figure 2, panel E) were more likely to adopt or maintain a healthy lifestyle (Figure 4). Thus, it is important to empower the motivation to change, as well as the self-regulation ability of cardiac rehabilitation patients regarding nutrition behavior. This can boost patients to eat healthier and to maintain or adopt PA. Referring back to hypothesis 4, the data support the assumption of a mediator. However, only the internal resource of FVC was revealed to be a mediator but no internal resources of PA or external resource of PA and FVC. Thus, hypothesis 4 was only partially supported.

\section{Limitations}

This study is subject to some limitations. First, as it was a small study, it provides only a limited sample size and power. Thus, the statistical analysis of chi-square could not be computed due to the small cell distributions. Second, all variables used in the study were self-report measures. Therefore, the inclusion of objective measures such as accelerometers, wearable cameras, or height and weight measurements is desirable in future studies. Third, physical health outcomes in the study only included BMI, which is too simple to reflect the comprehensive health situation of cardiac patients. More clinical health indicators such as blood pressure, total cholesterol, low-density lipoprotein cholesterol, high-density lipoprotein cholesterol, triglycerides, peak $\mathrm{VO}_{2}$, $\mathrm{VO}_{2} @ \mathrm{AT}$, and HR@AT should be added in the future. Fourth, only short-term effects were investigated. Long-term effects should be addressed in depth in the future with such an eHealth intervention. Fifth, patients received monetary incentives in exchange for their participation in the study, which might lead to a bias when evaluating the treatment effects. Moreover, the study could only include patients with access to a computer and the internet; therefore, the results cannot be generalized to patients without such access. Finally, although previously tested interventions in the Western Hemisphere [15,20] were tested with this study in the Eastern Hemisphere, no direct comparative study was conducted. It can only be concluded in this study that the intervention was as effective in Eastern Hemisphere as in Western Hemisphere. Future study should be warranted to test the same intervention in a comparative study to tease out differences in a systematic way.

\section{Conclusions}

To conclude, the study demonstrated the potential of a Web-based multiple health behavior intervention among Chinese rehabilitation patients with CHD. The majority of study hypotheses were supported. Such an intervention enriches the extended rehabilitation approaches for cardiac patients to be active and remain healthy in daily life when they are discharged from the hospital. The mechanism of exploration indicates that internal psychological resource (eg, high intention and good self-regulation capability) is a central variable and should especially be considered in cardiac patient health promotion. In addition, gateway or transfer effects, from 1 behavior to another, should be addressed in depth to explore synergetic effects.

\section{Acknowledgments}

This research was supported by a junior research group grant from the Wilhelm-Stiftung für Rehabilitationsforschung in Germany and Faculty Research Grant from Hong Kong Baptist University in Hong Kong (FRG1/12-13/064). All authors would like to 
thank Ms Guilan Wu, the chief nurse of Cardiac Rehabilitation Centre of Guangdong General Hospital, for her active assistance and engagement in recruiting cardiac patients during the research process.

\section{Conflicts of Interest}

None declared.

\section{Multimedia Appendix 1 \\ CONSORT - EHEALTH checklist (V 1.6.1). \\ [PDF File (Adobe PDF File), 440KB-Multimedia Appendix 1]}

\section{Multimedia Appendix 2}

Intervention variables and content.

[PNG File, 247KB-Multimedia Appendix 2]

\section{References}

1. World Health Organization. World health statistics 2018: monitoring health for the SDGs, sustainable development goals URL: http://www.who.int/gho/publications/world health statistics/2018/en/ [accessed 2018-10-28] [WebCite Cache ID 73V5mmK5b]

2. Chen WW, Gao RL, Liu LS, Zhu ML, Wang W, Wang YJ, et al. China Cardiovascular Disease Report 2017 (Summary) [In Chinese]. Chin Circ J 2018 Jan;33(1):1-8 [FREE Full text] [doi: 10.3969/j.issn.1000-3614.2018.01.001]

3. Taylor RS, Brown A, Ebrahim S, Jolliffe J, Noorani H, Rees K, et al. Exercise-based rehabilitation for patients with coronary heart disease: systematic review and meta-analysis of randomized controlled trials. Am J Med 2004 May 15;116(10):682-692. [doi: 10.1016/j.amjmed.2004.01.009] [Medline: 15121495]

4. Williams MA, Ades PA, Hamm LF, Keteyian SJ, LaFontaine TP, Roitman JL, et al. Clinical evidence for a health benefit from cardiac rehabilitation: an update. Am Heart J 2006 Nov;152(5):835-841. [doi: 10.1016/j.ahj.2006.05.015] [Medline: 17070142]

5. Wenger NK. Current status of cardiac rehabilitation. J Am Coll Cardiol 2008 Apr 29;51(17):1619-1631 [FREE Full text] [doi: 10.1016/j.jacc.2008.01.030] [Medline: 18436113]

6. Russell KL, Bray SR. Self-determined motivation predicts independent, home-based exercise following cardiac rehabilitation. Rehabil Psychol 2009 May;54(2):150-156. [doi: 10.1037/a0015595] [Medline: 19469604]

7. Lachat C, Otchere S, Roberfroid D, Abdulai A, Seret FM, Milesevic J, et al. Diet and physical activity for the prevention of noncommunicable diseases in low- and middle-income countries: a systematic policy review. PLoS Med 2013;10(6):e1001465 [FREE Full text] [doi: 10.1371/journal.pmed.1001465] [Medline: 23776415]

8. Schwarzer R. Modeling health behavior change: how to predict and modify the adoption and maintenance of health behaviors. Appl Psychol 2008 Jan;57(1):1-29. [doi: 10.1111/j.1464-0597.2007.00325.x]

9. Fleig L, Lippke S, Pomp S, Schwarzer R. Intervention effects of exercise self-regulation on physical exercise and eating fruits and vegetables: a longitudinal study in orthopedic and cardiac rehabilitation. Prev Med 2011 Sep;53(3):182-187. [doi: 10.1016/j.ypmed.2011.06.019] [Medline: 21784096]

10. Kordy H, Theis F, Wolf M. [Modern information and communication technology in medical rehabilitation. Enhanced sustainability through Internet-delivered aftercare]. Bundesgesundheitsblatt Gesundheitsforschung Gesundheitsschutz 2011 Apr;54(4):458-464. [doi: 10.1007/s00103-011-1248-7] [Medline: 21465402]

11. Liu SQ. Constructionanalysis of application effect of a new network platform in the high quality nursing system for CHD patients after PCI. J Qi Lu Nurs 2016 May;22(6):28-30 [FREE Full text] [doi: 10.3969/j.issn.1006-7256.2016.06.012]

12. Eysenbach G, CONSORT-EHEALTH Group. CONSORT-EHEALTH: improving and standardizing evaluation reports of Web-based and mobile health interventions. J Med Internet Res 2011 Dec 31;13(4):e126 [FREE Full text] [doi: 10.2196/jmir.1923] [Medline: 22209829]

13. Ritterband LM, Thorndike FP, Cox DJ, Kovatchev BP, Gonder-Frederick LA. A behavior change model for internet interventions. Ann Behav Med 2009 Aug;38(1):18-27 [FREE Full text] [doi: 10.1007/s12160-009-9133-4] [Medline: 19802647]

14. Reinwand DA, Crutzen R, Storm V, Wienert J, Kuhlmann T, de Vries H, et al. Generating and predicting high quality action plans to facilitate physical activity and fruit and vegetable consumption: results from an experimental arm of a randomised controlled trial. BMC Public Health 2016 Apr 12;16:317 [FREE Full text] [doi: 10.1186/s12889-016-2975-3] [Medline: 27066779]

15. Storm V, Dörenkämper J, Reinwand DA, Wienert J, De Vries H, Lippke S. Effectiveness of a web-based computer-tailored multiple-lifestyle intervention for people interested in reducing their cardiovascular risk: a randomized controlled trial. $\mathrm{J}$ Med Internet Res 2016 Apr 11;18(4):e78 [FREE Full text] [doi: 10.2196/jmir.5147] [Medline: 27068880] 
16. Widmer RJ, Allison TG, Keane B, Dallas A, Lerman LO, Lerman A. Using an online, personalized program reduces cardiovascular risk factor profiles in a motivated, adherent population of participants. Am Heart J 2014 Jan;167(1):93-100. [doi: 10.1016/j.ahj.2013.09.019] [Medline: 24332147]

17. Li L, Shao XP. Research progress of cardiac rehabilitation in patients with coronary heart disease. Nurs Integr Tradit Chin West Med 2017;3(7):32-35 [FREE Full text] [doi: 10.11997/nitcwm.201707011]

18. Wu Y, Chen MX. Research progress on web-based nursing intervention. Chin Nurs Res 2016 May;30(5):1552-1553 [FREE Full text] [doi: 10.3969/j.issn.1009-6493.2016.013.005]

19. Schwarzer R, Lippke S, Luszczynska A. Mechanisms of health behavior change in persons with chronic illness or disability: the Health Action Process Approach (HAPA). Rehabil Psychol 2011 Aug;56(3):161-170. [doi: 10.1037/a0024509] [Medline: 21767036]

20. Lippke S, Fleig L, Wiedemann AU, Schwarzer R. A computerized lifestyle application to promote multiple health behaviors at the workplace: testing its behavioral and psychological effects. J Med Internet Res 2015;17(10):e225 [FREE Full text] [doi: 10.2196/jmir.4486] [Medline: 26429115]

21. Tucker M, Reicks M. Exercise as a gateway behavior for healthful eating among older adults: an exploratory study. J Nutr Educ Behav 2002;34(Suppl 1):S14-S19. [doi: 10.1016/S1499-4046(06)60306-0] [Medline: 12047824]

22. Carraça EV, Silva MN, Coutinho SR, Vieira PN, Minderico CS, Sardinha LB, et al. The association between physical activity and eating self-regulation in overweight and obese women. Obes Facts 2013;6(6):493-506 [FREE Full text] [doi: 10.1159/000356449] [Medline: 24217426]

23. Schulz DN, Kremers SPJ, De Vries H. Tailored eHealth lifestyle promotion: which behavioral modules do users prefer? J Health Commun 2015;20(6):663-672. [doi: 10.1080/10810730.2015.1012243] [Medline: 25928161]

24. Michie S, Ashford S, Sniehotta FF, Dombrowski SU, Bishop A, French DP. A refined taxonomy of behaviour change techniques to help people change their physical activity and healthy eating behaviours: the CALO-RE taxonomy. Psychol Health 2011 Nov;26(11):1479-1498. [doi: 10.1080/08870446.2010.540664] [Medline: 21678185]

25. Duan YP, Wienert J, Hu C, Si GY, Lippke S. Web-based intervention for physical activity and fruit and vegetable intake among Chinese university students: a randomized controlled trial. J Med Internet Res 2017 Apr 10;19(4):e106 [FREE Full text] [doi: 10.2196/jmir.7152] [Medline: 28396306]

26. Macfarlane DJ, Lee CC, Ho EY, Chan KL, Chan DT. Reliability and validity of the Chinese version of IPAQ (short, last 7 days). J Sci Med Sport 2007 Feb;10(1):45-51. [doi: 10.1016/j.jsams.2006.05.003] [Medline: 16807105]

27. Rafferty AP, Anderson JV, McGee HB, Miller CE. A healthy diet indicator: quantifying compliance with the dietary guidelines using the BRFSS. Prev Med 2002 Jul;35(1):9-15. [doi: 10.1006/pmed.2002.1056] [Medline: 12079436]

28. LeFevre ML, US Preventive Services Task Force. Behavioral counseling to promote a healthful diet and physical activity for cardiovascular disease prevention in adults with cardiovascular risk factors: U.S. Preventive Services Task Force Recommendation Statement. Ann Intern Med 2014 Oct 21;161(8):587-593. [doi: 10.7326/M14-1796] [Medline: 25155419]

29. Aune D, Giovannucci E, Boffetta P, Fadnes LT, Keum N, Norat T, et al. Fruit and vegetable intake and the risk of cardiovascular disease, total cancer and all-cause mortality-a systematic review and dose-response meta-analysis of prospective studies. Int J Epidemiol 2017 Dec 01;46(3):1029-1056 [FREE Full text] [doi: 10.1093/ije/dyw319] [Medline: 28338764]

30. Lippke S, Ziegelmann JP, Schwarzer R, Velicer WF. Validity of stage assessment in the adoption and maintenance of physical activity and fruit and vegetable consumption. Health Psychol 2009 Mar;28(2):183-193 [FREE Full text] [doi: 10.1037/a0012983] [Medline: 19290710]

31. Luszczynska A, Sutton S. Physical activity after cardiac rehabilitation: evidence that different types of self-efficacy are important in maintainers and relapsers. Rehabil Psychol 2006;51(4):314-321. [doi: 10.1037/0090-5550.51.4.314]

32. Luszczynska A, Tryburcy M, Schwarzer R. Improving fruit and vegetable consumption: a self-efficacy intervention compared with a combined self-efficacy and planning intervention. Health Educ Res 2007 Oct;22(5):630-638. [doi: 10.1093/her/cyl133] [Medline: 17060349 ]

33. Lippke S, Schwarzer R, Ziegelmann JP, Scholz U, Schüz B. Testing stage-specific effects of a stage-matched intervention: a randomized controlled trial targeting physical exercise and its predictors. Health Educ Behav 2010 Aug;37(4):533-546. [doi: 10.1177/1090198109359386] [Medline: 20547760]

34. Jackson J, Lippke S, Gray C. Stage-specific prediction of physical activity in orthopaedic patients after rehabilitation treatment. Int J Sport Psychol 2011;42(6):586-609 [FREE Full text]

35. Yao G, Wu C. Similarities and differences among the Taiwan, China, and Hong-Kong versions of the WHOQOL Questionnaire. Soc Indic Res 2008 Sep 30;91(1):79-98. [doi: 10.1007/s11205-008-9326-4]

36. Rankin SH, Galbraith ME, Johnson S. Reliability and validity data for a Chinese translation of the Center for Epidemiological Studies-Depression. Psychol Rep 1993 Dec;73(3 Pt 2):1291-1298. [doi: 10.2466/pr0.1993.73.3f.1291] [Medline: $\underline{\text { 8115582] }}$

37. Preacher KJ, Hayes AF. Asymptotic and resampling strategies for assessing and comparing indirect effects in multiple mediator models. Behav Res Methods 2008 Aug;40(3):879-891. [doi: 10.3758/BRM.40.3.879] [Medline: 18697684]

38. Schroeder MA. Diagnosing and dealing with multicollinearity. West J Nurs Res 1990 Apr;12(2):175-184. [doi: 10.1177/019394599001200204] [Medline: 2321373] 
39. Schafer JL, Olsen MK. Multiple imputation for multivariate missing-data problems: a data analyst's perspective. Multivariate Behav Res 1998 Oct 01;33(4):545-571. [doi: 10.1207/s15327906mbr3304 5] [Medline: 26753828]

40. Avram C, Iurciuc M, Craciun L, Avram A, Iurciuc S, Oancea C, et al. Dietary and physical activity counseling in high-risk asymptomatic patients with metabolic syndrome?A primary care intervention. J Food Agric Environ 2011 Jan 1;9(3\&4):16-19 [FREE Full text]

41. Gomez-Huelgas R, Jansen-Chaparro S, Baca-Osorio AJ, Mancera-Romero J, Tinahones FJ, Bernal-López MR. Effects of a long-term lifestyle intervention program with Mediterranean diet and exercise for the management of patients with metabolic syndrome in a primary care setting. Eur J Intern Med 2015 Jun;26(5):317-323. [doi: 10.1016/j.ejim.2015.04.007] [Medline: 25907985]

42. Wieland LS, Falzon L, Sciamanna CN, Trudeau KJ, Brodney S, Schwartz JE, et al. Interactive computer-based interventions for weight loss or weight maintenance in overweight or obese people. Cochrane Database Syst Rev 2012;8:CD007675 [FREE Full text] [doi: 10.1002/14651858.CD007675.pub2] [Medline: 22895964]

43. Wang W, Chair SY, Thompson DR, Twinn SF. Effects of home-based rehabilitation on health-related quality of life and psychological status in Chinese patients recovering from acute myocardial infarction. Heart Lung 2012;41(1):15-25. [doi: 10.1016/j.hrtlng.2011.05.005] [Medline: 21974926]

44. Fleig L, Kerschreiter R, Schwarzer R, Pomp S, Lippke S. 'Sticking to a healthy diet is easier for me when I exercise regularly': cognitive transfer between physical exercise and healthy nutrition. Psychol Health 2014 Jul;29(12):1361-1372. [doi: 10.1080/08870446.2014.930146] [Medline: 24894668]

45. Schulz DN, Kremers SP, De Vries H. Tailored eHealth lifestyle promotion: which behavioral modules do users prefer? J Health Commun 2015;20(6):663-672. [doi: 10.1080/10810730.2015.1012243] [Medline: 25928161]

\author{
Abbreviations \\ ANOVA: analysis of variance \\ ANCOVA: analyses of covariance \\ BMI: body mass index \\ CHD: coronary heart disease \\ CVD: cardiovascular disease \\ eHealth: electronic health \\ FVC: fruit and vegetable consumption \\ HAPA: Health Action Process Approach \\ IG: intervention group \\ PA: physical activity \\ OR: odds ratio \\ VIF: variance inflation factor \\ WCG: waiting control group
}

Edited by G Eysenbach; submitted 28.08.18; peer-reviewed by R Schwarzer, $R$ Wurst; comments to author 08.10.18; revised version
received 20.10.18; accepted 20.10.18; published 19.11.18
Please cite as:
Duan YP, Liang W, Guo L, Wienert J, Si GY, Lippke S
Evaluation of a Web-Based Intervention for Multiple Health Behavior Changes in Patients With Coronary Heart Disease in Home-Based
Rehabilitation: Pilot Randomized Controlled Trial
J Med Internet Res 2018;20(11):e12052
URL: http://www.jmir.org/2018/11/e12052/
doi: 1 10.2196/12052
PMID: $\underline{30455167}$

(C) Yan Ping Duan, Wei Liang, Lan Guo, Julian Wienert, Gang Yan Si, Sonia Lippke. Originally published in the Journal of Medical Internet Research (http://www.jmir.org), 19.11.2018. This is an open-access article distributed under the terms of the Creative Commons Attribution License (https://creativecommons.org/licenses/by/4.0/), which permits unrestricted use, distribution, and reproduction in any medium, provided the original work, first published in the Journal of Medical Internet Research, is properly cited. The complete bibliographic information, a link to the original publication on http://www.jmir.org/, as well as this copyright and license information must be included. 